\title{
Coexistence of fibromyalgia and metabolic syndrome in females: The effects on fatigue, clinical features, pain sensitivity, urinary cortisol and norepinephrine levels: A cross-sectional study
}

\author{
Onat Çakit ${ }^{1}\left(\mathbb{D}\right.$, Alper Gümüştepe $^{2}\left(\mathbb{D}\right.$, Burcu Duyur Çakıt $^{3}{ }^{\circledR}$, Seçil Pervane Vural ${ }^{3} \mathbb{C}$, \\ Tuba Özgün ${ }^{4}$ (D), Hakan Genç3(D) \\ ${ }^{1}$ Department of Family Medicine, University of Health Sciences, Ankara Training and Research Hospital, Ankara, Turkey \\ ${ }^{2}$ Department of Physical Medicine and Rehabilitation, Kahramankazan Goverment Hospital, Ankara, Turkey \\ ${ }^{3}$ Department of Physical Medicine and Rehabilitation, University of Health Sciences, Ankara Training and Research Hospital, Ankara, Turkey \\ ${ }^{4}$ Department of Biochemistry, University of Health Sciences, Ankara Training and Research Hospital, Ankara, Turkey
}

\begin{abstract}
Objectives: This study aims to evaluate the coexistence of metabolic syndrome (MetS) and fibromyalgia syndrome (FMS) and determine the effects of this coexistence on neuroendocrine levels and clinical features of FMS.

Patients and methods: One-hundred female FMS patients (mean age: $40.1 \pm 7.8$ years; range, 24 to 58 years) and 38 healthy females (mean age: $40.4 \pm 5.8$ years; range, 30 to 55 years) were included in this cross-sectional study. MetS was identified by using the criteria from the Adult Treatment Panel III. Widespread pain index, symptom severity score and number of tender points were determined. Visual analog scale, Fibromyalgia Impact Questionnaire, Fatigue Severity Scale, Beck Depression Inventory, and pain pressure threshold were used as the outcome measures. The severity of FMS was assessed with total myalgic score (TMS) and control point score.

Results: Twenty-four (24\%) of the 100 FMS patients and three (7.9\%) of the 38 control patients fulfilled the MetS criteria ( $p=0.047)$. The coexistence of FMS and MetS was associated with higher symptom severity score $(p=0.004)$, widespread pain index $(p=0.001)$, number of tender points $(p=0.039)$, and lower total myalgic score $(p=0.029)$ values. There was a significant association between the occurrence of FMS and MetS (odds ratio=3.76; $95 \%$ confidence interval: $1.04-13.4 ; p=0.043)$.

Conclusion: We found that patients with FMS had a nearly four times higher risk for MetS and the coexisting MetS may increase the severity of FMS. In clinical practice, when evaluating a patient with FMS, metabolic characteristics should also be evaluated.

Keywords: Fibromyalgia, metabolic syndrome, obesity, pain pressure threshold.
\end{abstract}

Fibromyalgia syndrome (FMS) is a condition characterized by widespread pain, muscle tenderness, and decreased pain threshold to pressure. ${ }^{1}$ The pathophysiology of FMS is still unknown. Abnormal regulation of central pain modulation, ${ }^{2}$ dysregulated hypothalamic-pituitaryadrenal axis, ${ }^{3}$ and immunologic sensitivity ${ }^{4}$ are thought to augment pain associated with disability in FMS patients. These dysregulations and sensitivity are also found in obesity and metabolic syndrome (MetS). ${ }^{1}$ The prevalence rates of MetS are known to increase with obesity and physical inactivity. ${ }^{5}$ Sleep disturbances have also been associated with the development of MetS. ${ }^{6}$ Sleep disturbances and disability due to reduced physical activity are among the other characteristics of FMS.7 Since these clinical features intrinsic to FMS are also associated with MetS, patients

Received: April 03, 2019 Accepted: January 03, 2020 Published online: June 25, 2020

Correspondence: Seçil Pervane Vural, MD. SBÜ Ankara Eğitim ve Araştırma Hastanesi Fizik Tedavi ve Rehabilitasyon Kliniği, 06230 Altındağ, Ankara, Türkiye. Tel: +90 532 - 3856988 e-mail: secilvural@hotmail.com 
with FMS might be at greater risk for metabolic problems. $^{8}$

There is, however, only limited data concerning the relationship between FMS and metabolic disturbances. Patients with FMS commonly have an elevated prevalence of overweight and obesity, ${ }^{3,9}$ insulin resistance, ${ }^{10}$ diabetes mellitus, ${ }^{11}$ and MetS. ${ }^{8}$ Higher triglycerides and total cholesterol, as well as a higher prevalence of MetS have been observed in a cohort of fibromyalgia patients compared to controls. ${ }^{8}$ MetS indicates risk for cardiovascular disease, diabetes mellitus, and all-cause mortality. 8,12 As defined by the Adult Treatment Panel III, MetS is a composition of central obesity, dyslipidemia, hypertension, and glucose intolerance. ${ }^{12}$ There are several similarities between FMS and MetS. Both have been characterized by sympathetic nervous system activation as evidenced by lowered heart rate variability and elevated norepinephrine (NE) levels, ${ }^{1,13,14}$ although peripheral samples do not always demonstrate these findings. ${ }^{15,16}$ In addition, both MetS and FMS have been associated with perturbations of hypothalamic-pituitary-adrenal axis, while the literature findings are controversial reporting mild hypercortisolism, hypercortisolism, and a flattening of the cortisol diurnal curve. ,13,17,18 $^{-13}$

To our knowledge, the coexistence of MetS in FMS patients and factors that contribute to the association between FMS and MetS are not fully established. Furthermore, the effects of the coexistence of MetS and FMS on the clinical and neuroendocrine features of the latter have not been well investigated. Therefore, in this study, we aimed to evaluate the coexistence of MetS and FMS and determine the effects of this coexistence on the neuroendocrine levels and clinical features of FMS.

\section{PATIENTS AND METHODS}

This cross-sectional study was conducted between February 2016 and September 2018 at Ankara Training and Research Hospital. The estimated sample size was calculated using $\mathrm{G}^{*}$ Power $^{\odot} 3.1$ program (Heinrich-HeineUniversität Düsseldorf, Düsseldorf, Germany) based on the study of Loevinger et $a{ }^{8}$ The study initially included 150 female FMS patients and 50 healthy female hospital workers. All patients fulfilled the 2010 American College of Rheumatology preliminary diagnostic criteria for FMS. ${ }^{19}$ At the beginning of the study, medical histories of all recruited patients were recorded. The patients that had acute infectious disease within the previous three weeks, those with autoimmune, chronic or inflammatory diseases, vitamin $\mathrm{D}$ and iron deficiency, medical conditions requiring glucocorticoid treatment and those who were pregnant were excluded. Thyroid, liver or renal diseases, which are known to be associated with MetS, were also accepted as the exclusion criteria. Since males formed a more uniform patient sample with very low prevalence of FMS compared to females, they were excluded. Thirty-five individuals were excluded from the study based on the exclusion criteria. In addition, 15 patients refused to participate in the study. Furthermore, of the 50 healthy female hospital workers initially considered for the study as the control group, 12 were excluded based on the same exclusion criteria. As a result, a total of 100 female FMS patients (mean age: $40.1 \pm 7.8$ years; range, 24 to 58 years) and 38 female controls (mean age: $40.4 \pm 5.8$ years; range, 30 to 55 years) constituted the sample of the study (Figure 1). The study protocol was approved by the Ankara Training and Research Hospital Ethics Committee. A written informed consent was obtained from each participant. The study was conducted in accordance with the principles of the Declaration of Helsinki.

The demographics and medical histories of the patients were evaluated. Fasting glucose and insulin values, glycated hemoglobin, blood lipid profile, thyroid function tests, complete blood count, blood chemistry, iron, folic acid, and vitamin B12 levels of the participants were studied. The body mass index (BMI) was calculated as weight in kilograms divided by the square of the height in meters. Normal weight was defined as BMI 18.5-24.9, overweight as BMI 25.0-29.0, and obesity as BMI $\geq 30$ according to the World Health Organization (WHO) classification criteria. ${ }^{20}$

Waist circumference and waist/hip ratio were used to assess body fat distribution and specifically as indicators of intraabdominal or visceral fat deposition. The anthropometric assessments were performed by the first author. All subjects wore light clothes and no shoes. The total body weight was measured using a stable digital portable 


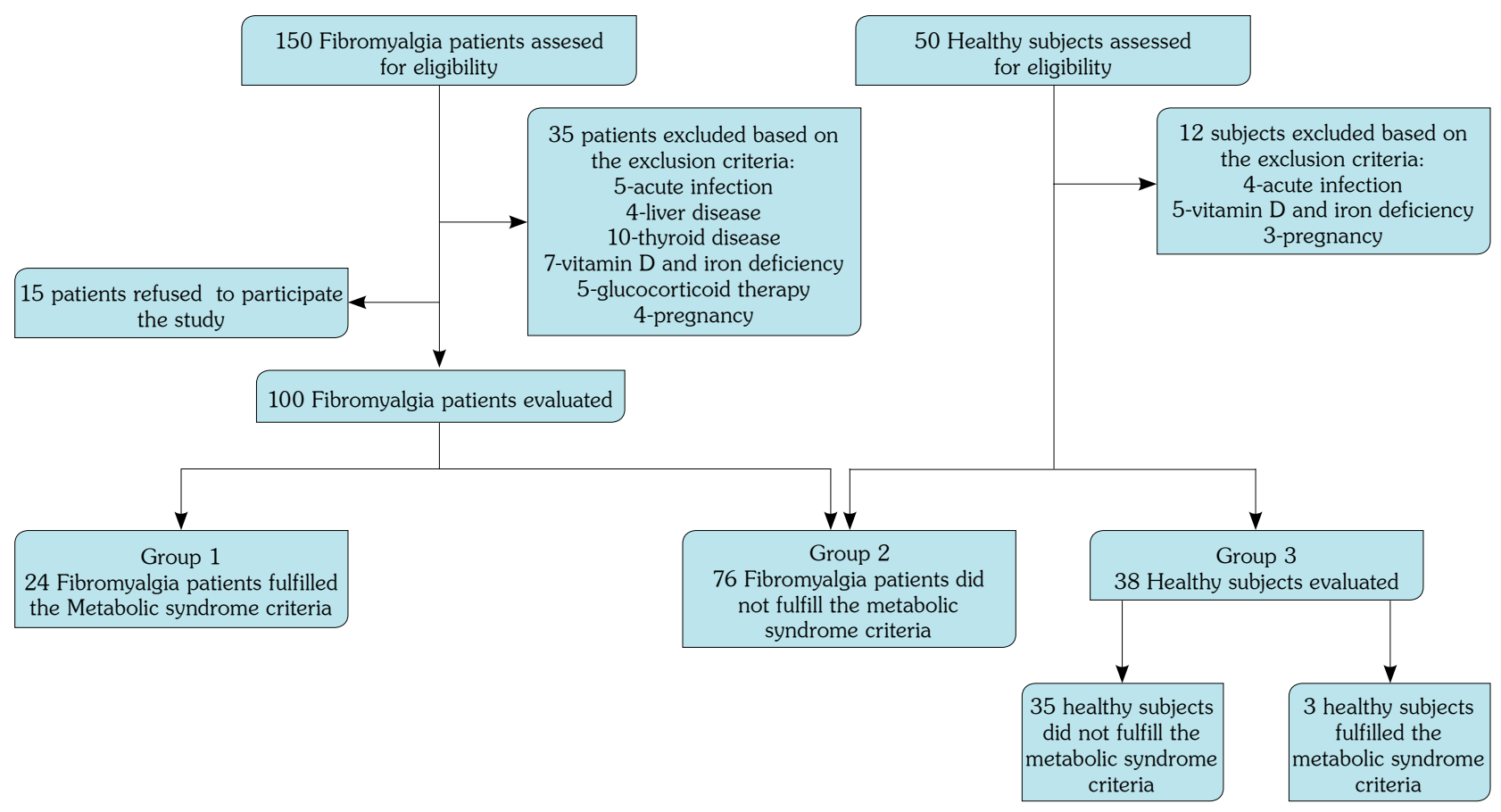

Figure 1. Flow diagram of study.

scale with precision of $0.5 \mathrm{~kg}$. Body height was measured with the subject standing barefoot with heels together, arms at the side, legs straight, shoulders relaxed, and the head in the horizontal plane. Waist circumference was measured using a spring scale while the subject was standing and wearing only underwear, at the end of gentle expiration at the level midway between the lower rib margin and the iliac crest (the cut-off point for cardiovascular disease risk was $88 \mathrm{~cm}$ for females as defined in the criteria of the WHO). Hip circumference was measured at the largest posterior extension of the buttocks. Waist/hip ratio was calculated by dividing these two values (the cut-off point for cardiovascular disease risk was 0.85 in females as defined in the criteria of the WHO). ${ }^{21}$

The diagnosis of MetS was established depending on the presence of at least three of the following parameters according to Adult Treatment Panel III-2001 criteria: abdominal obesity (increased waist circumference $102 \mathrm{~cm}$ for males and $88 \mathrm{~cm}$ for females), hypertension (systolic blood pressure [SBP] and diastolic blood pressure $[\mathrm{DBP}] \geq 130 / 85 \mathrm{mmHg}$ ) or history of antihypertensive usage, hypertriglyceridemia
( $\geq 150 \mathrm{mg} / \mathrm{dL}$ ) or presence of treatment for this disorder, low high-density lipoprotein (HDL) cholesterol $(<40 \mathrm{mg} / \mathrm{dL}$ in males and $<50 \mathrm{mg} / \mathrm{dL}$ in females) and high fasting plasma glucose $(\geq 110 \mathrm{mg} / \mathrm{dL})$ or presence of diagnosis of type 2 diabetes mellitus. The primary clinical outcome of MetS was identified as coronary heart disease/cardiovascular disease. ${ }^{12}$ Resting blood pressure (BP) was manually recorded in seated participants as the average of two measurements taken from the same arm.

Insulin resistance was calculated by the homeostasis model assessment (HOMA) formula (basal plasma glucose $[\mathrm{mg} / \mathrm{dL}] \times$ basal plasma insulin $[\mathrm{UI} / \mathrm{mL}] / 405)$. The cut-off value for insulin resistance was HOMA $>2.7 .{ }^{22}$ Glycated hemoglobin level was evaluated and a glycated hemoglobin level greater than 5.5\% was associated with a significantly elevated cardiovascular risk. ${ }^{23}$

The Visual Analog Scale (VAS) was used to measure the intensity of pain (from 0 indicating no pain to 10 indicating the most severe pain ever experienced). The participants in both groups also completed the Beck Depression Inventory (BDI), a 21-item questionnaire frequently used 
to measure depression in patients with chronic pain. ${ }^{24,25}$ According to the 2010 American College of Rheumatology preliminary diagnostic criteria for FMS, widespread pain index scores and symptom severity scores were determined. Tender point and control point examinations in the patients and controls were performed with a Fisher's tissue compliance meter, which is also used as a pressure pain algometer. ${ }^{26}$ Eighteen tender points and four control points (mid-thigh and thumbnail-bilateral) were evaluated. The patients were instructed to indicate when they first perceived pain. They were also informed that the investigation was aimed at determining the pain threshold, not pain tolerance. Then, pressure was increased at the rate of $1 \mathrm{~kg} / \mathrm{second}$ until pain or discomfort occurred; the minimum force that caused pain was termed as the pain pressure threshold (PPT). A mean value of three measurements on each selected measuring point was used for determination of the PPT. The points that were painful with less than $4 \mathrm{~kg} / \mathrm{cm}^{2}$ pressure were accepted as tender points. The tender point counts were noted. The severity of FMS was assessed based on total myalgic score (TMS) and control point score (CPS). The sum of the PPT of all 22 points (18 tender points and four control points) was calculated as TMS $\left(\mathrm{kg} / \mathrm{cm}^{2}\right)$ and the sum of those of the control points was recorded as CPS $\left(\mathrm{kg} / \mathrm{cm}^{2}\right)$.

The participants completed an overnight urine collection that began 12 hours before their wake-up time. Urinary cortisol, urinary NE, and plasma cortisol levels were determined. Urinary creatinine levels were measured and creatinine adjustment was undertaken to correct for low volume or incomplete void collection, and then the tests were repeated for these low or incomplete samples.

Fatigue was evaluated using the Turkish version of the fatigue severity scale (FSS). ${ }^{27}$ Current health status was evaluated using the Turkish version of the Fibromyalgia Impact Questionnaire (FIQ), which is a brief 10 -item, self-administered instrument that measures physical functioning, work status, depression, anxiety, sleep, pain, stiffness, fatigue, and well being. ${ }^{28}$

After the evaluation, the study group was subdivided into three groups: group 1 consisting of comorbid FMS+MetS patients, group 2 comprising pure FMS patients, and group 3 containing the controls.

\section{Statistical analysis}

All statistical analyses were performed using the SPSS for Windows version 15.0 software (SPSS Inc., Chicago, IL, USA). Normality was assessed by skewness and kurtosis. Descriptive statistics were presented as means (standard deviations) for continuous variables and count (percentage) for nominal variables. All values were normally distributed. One-way analysis of variance (ANOVA) was performed on the data obtained from the two patient groups and the control group. Tukey's post hoc tests were conducted when ANOVA showed significant effects. The results were reported as mean \pm standard deviation. A chi-square test was performed to compare prevalence. Univariate logistic regression analysis was performed to assess the association between MetS or its individual components and FMS. The odds ratio (OR) and 95\% confidence interval (CI) of FMS according to the number of components of MetS were also assessed. Stepwise linear regression analysis was undertaken to identify the factors affecting the FIQ.

\section{RESULTS}

Of the 100 FMS patients examined, 24 fulfilled (group 1) and 76 did not fulfill (group 2) the MetS criteria. Of the 38 controls (group 3) examined, three fulfilled these criteria. Table 1 shows the characteristics of the participants according to the presence of MetS. The age and BMI levels were similar in the three groups $(p>0.05)$. Post hoc power analysis was performed to calculate achieved power of one-way ANOVA with TMS. Sample sizes of 24, 76 and 38 obtained from the three groups, whose means were to be compared, achieved $99 \%$ power to detect differences among the means versus the alternative of equal means using an $\mathrm{F}$ test with a 0.05 significance level and an effect size (partial eta squared) of 0.63 .

Compared to the healthy females, the group 1 and group 2 had higher VAS, number of tender points, CPS, FSS, and BDI values $(p<0.001$ for all). In contrast, the group 1 and group 2 did not differ in terms of VAS, CPS, FSS, FIQ, and 
Table 1. Clinical and demographic characteristics of patient and control groups

\begin{tabular}{|c|c|c|c|c|c|c|c|c|c|c|}
\hline & \multicolumn{3}{|c|}{$\begin{array}{c}\text { FMS with MetS }(\mathrm{n}=24) \\
\text { Group } 1\end{array}$} & \multicolumn{3}{|c|}{$\begin{array}{l}\text { FMS without MetS }(\mathrm{n}=76) \\
\text { Group } 2\end{array}$} & \multicolumn{3}{|c|}{$\begin{array}{l}\text { Control }(n=38) \\
\text { Group } 3\end{array}$} & \multirow[b]{2}{*}{$p$} \\
\hline & $\mathrm{n}$ & $\%$ & Mean \pm SD & $\mathrm{n}$ & $\%$ & Mean \pm SD & $\mathrm{n}$ & $\%$ & Mean \pm SD & \\
\hline Age (year) & & & $41.1 \pm 7.8$ & & & $39.7 \pm 7.8$ & & & $40.4 \pm 5.8$ & $>0.05$ \\
\hline Body mass index $\left(\mathrm{kg} / \mathrm{m}^{2}\right)$ & & & $29.0 \pm 4.7$ & & & $28.1 \pm 4.9$ & & & $27.5 \pm 3.8$ & $>0.05$ \\
\hline $\begin{array}{l}\text { Body mass index }\left(\mathrm{kg} / \mathrm{cm}^{2}\right) \\
\text { Obese }(>30) \\
\text { Overweight }(25-29.9) \\
\text { Normoweight }(18.5-24.9)\end{array}$ & $\begin{array}{l}13 \\
7 \\
4\end{array}$ & $\begin{array}{l}54.2 \\
29.2 \\
16.7\end{array}$ & & $\begin{array}{l}18 \\
29 \\
29\end{array}$ & $\begin{array}{l}23.7 \\
38.2 \\
38.2\end{array}$ & & $\begin{array}{c}6 \\
13 \\
19\end{array}$ & $\begin{array}{c}15.8 \\
34.2 \\
50\end{array}$ & & $\begin{array}{c}0.019 \dagger^{*} \\
0.06 \neq^{*} \\
>0.05 q^{*}\end{array}$ \\
\hline Visual Analog Scale & & & $7.5 \pm 0.9$ & & & $6.6 \pm 1.5$ & & & $4.3 \pm 2.5$ & $\begin{array}{l}>0.05 \dagger \\
<0.001 \neq, \pi\end{array}$ \\
\hline Antidepressant usage & 16 & 66.7 & & 32 & 42.1 & & - & - & & 0.031 \\
\hline Symptom severity (0-12) & & & $10.3 \pm 1.6$ & & & $8.4 \pm 2.4$ & & & & 0.004 \\
\hline Widespread Pain Index (0-19) & & & $15.7 \pm 2.5$ & & & $12.5 \pm 3.2$ & & & - & 0.001 \\
\hline Number of tender points $(0-18)$ & & & $16.8 \pm 1.3$ & & & $15.6 \pm 2.4$ & & & $6.8 \pm 1.8$ & $\begin{array}{c}0.039 \dagger \\
<0.001 \neq, \text {, }\end{array}$ \\
\hline Control point score & & & $11.5 \pm 4.9$ & & & $14.9 \pm 7.2$ & & & $29.0 \pm 6.5$ & $\begin{array}{c}>0.05 \dagger \\
<0.001 \neq,, \mathbb{T}\end{array}$ \\
\hline Total myalgic score $\left(\mathrm{kg} / \mathrm{cm}^{2}\right)$ & & & $50.8 \pm 17.0$ & & & $63.8 \pm 23.9$ & & & $123.3 \pm 23.9$ & $\begin{array}{c}0.029 \dagger \\
<0.001 \neq, \pi\end{array}$ \\
\hline Fatigue severity scale & & & $55.6 \pm 12.2$ & & & $53.0 \pm 13.9$ & & & $30.9 \pm 18.7$ & $\begin{array}{l}>0.05 \dagger \\
<0.001 \neq, \mathbb{T}\end{array}$ \\
\hline Fibromyalgia impact questionnaire & & & $52.4 \pm 14.7$ & & & $52.1 \pm 14.0$ & & & $34.0 \pm 19.2$ & $\begin{array}{l}<0.001 \neq, \text {, } \\
>0.05 \dagger\end{array}$ \\
\hline Beck depression inventory & & & $24.4 \pm 12.2$ & & & $24.5 \pm 12.6$ & & & $12.5 \pm 10.8$ & $\begin{array}{l}<0.001 \neq, \mathbb{1} \\
>0.05 \dagger\end{array}$ \\
\hline
\end{tabular}

BDI values ( $p>0.05)$. On the other hand, the symptom severity $(p=0.004)$, widespread pain index $(p=0.001)$ and number of tender points $(p=0.039)$ values were higher and the TMS values $(p=0.029)$ were lower in group 1 (Table 1$)$.

Body mass index values were similar in all groups ( $p>0.05)$; however, the number of obese patients was higher in group 1 (Table 1). Waist circumference $(p<0.001, p=0.001$, respectively), hip circumference $(p=0.037, \quad p=0.006$, respectively) and waist/hip ratio values $(p=0.037$, $p<0.001$, respectively) were higher in group 1 than group 2 and group 3. Waist circumference and hip circumference were not different ( $p>0.05)$, while waist/hip ratio was slightly higher in group 2 than group $3(p=0.045)$. The mean glycated hemoglobin $(p=0.002$ and $p<0.001$, respectively) and triglyceride (both $p<0.001$ ) values were higher and HDL values were lower ( $p=0.009$ and $p=0.045$, respectively) in group 1 than group 2 and group 3. The mean SBP $(p<0.001$ and $p=0.004$, respectively) and DBP $(p=0.003$ and $p=0.006$, respectively) were higher in all groups. However, the mean triglyceride, HDL, SBP and DBP values were not different between the three groups ( $p>0.05)$. Despite high BP values, the antihypertensive usage rates were very low in the two patient groups (Table 2). The urinary cortisol, urinary NE, plasma cortisol, thyroidstimulating hormone, T3, T4, Fe, folic acid, and vitamin B12 levels did not differ between the three groups ( $p>0.05$ ).

The fasting plasma glucose values were significantly higher in group $1(p<0.001)$, while they did not differ between group 2 and group 3 ( $p>0.05$ ). The mean glycated hemoglobin values were higher in group 1 than in group 2 and group 3 ( $p=0.02$ and $p<0.001$, respectively), but they were not different between group 2 and group 3 ( $p>0.05)$. The number of patients 
Table 2. Metabolic characteristics of patient and control groups

\begin{tabular}{|c|c|c|c|c|c|c|c|c|c|c|}
\hline & \multicolumn{3}{|c|}{$\begin{array}{l}\text { FMS with MetS (n=24) } \\
\text { Group } 1\end{array}$} & \multicolumn{3}{|c|}{$\begin{array}{l}\text { FMS without MetS }(\mathrm{n}=76) \\
\text { Group } 2\end{array}$} & \multicolumn{3}{|c|}{$\begin{array}{l}\text { Control }(\mathrm{n}=38) \\
\text { Group } 3\end{array}$} & \multirow[b]{2}{*}{$p$} \\
\hline & $\mathrm{n}$ & $\%$ & Mean \pm SD & $\mathrm{n}$ & $\%$ & Mean \pm SD & $\mathrm{n}$ & $\%$ & Mean \pm SD & \\
\hline Waist circumference $(\mathrm{cm})$ & & & $95.5 \pm 10.3$ & & & $84.8 \pm 12.1$ & & & $84.4 \pm 9.4$ & $\begin{array}{l}<0.001 \dagger \\
0.001 \neq \\
>0.059\end{array}$ \\
\hline Hip circumference $(\mathrm{cm})$ & & & $108.2 \pm 7.5$ & & & $103.1 \pm 9.2$ & & & $101.3 \pm 6.9$ & $\begin{array}{l}0.037 \dagger \\
0.006 \neq \\
>0.059\end{array}$ \\
\hline Waist/hip ratio & & & $0.9 \pm 0.1$ & & & $0.8 \pm 0.1$ & & & $0.8 \pm 0.1$ & $\begin{array}{c}0.037 \dagger \\
<0.001 \ddagger \\
0.0459\end{array}$ \\
\hline Fasting plasma glucose (mg/dL) & & & $122.2 \pm 6.8$ & & & $93.8 \pm 10.8$ & & & $93.3 \pm 10.4$ & $\begin{array}{l}<0.001 \dagger, \neq \\
>0.059\end{array}$ \\
\hline Fasting plasma insulin (UI/mL) & & & $11.2 \pm 6.3$ & & & $10.4 \pm 7.2$ & & & $6.6 \pm 3.7$ & $\begin{array}{c}0.03 \ddagger \\
0.0139 \\
>0.05 \dagger\end{array}$ \\
\hline Glycated hemoglobin $(\mathrm{mmol} / \mathrm{mol})$ & & & $6.4 \pm 1.9$ & & & $5.6 \pm 0.5$ & & & $5 . \pm 0.5$ & $\begin{array}{c}0.002 \dagger \\
<0.001 \ddagger \\
>0.059\end{array}$ \\
\hline $\begin{array}{l}\text { HOMA-index } \\
\quad \text { a.HOMA-index+BMI }>30 \\
\text { b.HOMA-index+BMI 25-29.9 } \\
\text { c.HOMA-index+BMI 18.5-24.9 }\end{array}$ & & & $\begin{array}{l}3.2 \pm 1.7 \\
3.5 \pm 1.9 \\
3.4 \pm 1.4 \\
1.2 \pm 0.4\end{array}$ & & & $\begin{array}{l}2.4 \pm 1.7 \\
2.7 \pm 1.7 \\
2.3 \pm 1.8 \\
2.2 \pm 1.6\end{array}$ & & & $\begin{array}{l}1.5 \pm 0.8 \\
2.1 \pm 0.8 \\
1.7 \pm 0.9 \\
1.0 \pm 0.3\end{array}$ & $\begin{array}{l}<0.001 \neq \\
0.0149 \\
>0.05 \dagger\end{array}$ \\
\hline Triglycerides (mg/dL) & & & $189.5 \pm 83.9$ & & & $118.6 \pm 51.2$ & & & $110.5 \pm 39.8$ & $\begin{array}{l}<0.001 \dagger, \neq \\
>0.059\end{array}$ \\
\hline Total cholesterol (mg/dL) & & & $213.3 \pm 44.2$ & & & $193.9 \pm 40.0$ & & & $184.7 \pm 34.8$ & $\begin{array}{c}0.02 \ddagger \\
>0.05+, \mathbb{T}\end{array}$ \\
\hline $\mathrm{HDL}(\mathrm{mg} / \mathrm{dL})$ & & & $42.7 \pm 8.1$ & & & $49.0 \pm 9.6$ & & & $48.4 \pm 7.7$ & $\begin{array}{l}0.009 \dagger \\
0.045 \ddagger \\
>0.059\end{array}$ \\
\hline $\mathrm{LDL}(\mathrm{mg} / \mathrm{dL})$ & & & $132.9 \pm 36.5$ & & & $119.8 \pm 33.0$ & & & $116.8 \pm 31.1$ & $>0.05 \dagger, \neq, \mathbb{Q}$ \\
\hline Antihypertensive usage & 7 & 29.2 & & 6 & 7.9 & & 7 & 18.4 & & $\begin{array}{c}0.013 \dagger^{*} \\
0.001 \neq^{*} \\
>0.05 q^{*}\end{array}$ \\
\hline Hypertension (>130/85) & 17 & 70.8 & & 19 & 25.0 & & - & - & & \\
\hline Systolic pressure $(\mathrm{mmHg})$ & & & $135.6 \pm 24.0$ & & & $117.1 \pm 15.6$ & & & $120.5 \pm 16.7$ & $\begin{array}{c}<0.001 \dagger \\
0.004 \ddagger \\
>0.059\end{array}$ \\
\hline Diastolic pressure $(\mathrm{mmHg})$ & & & $82.3 \pm 13.4$ & & & $72.4 \pm 9.3$ & & & $76.6 \pm 10.1$ & $\begin{array}{l}0.003 \dagger \\
0.006 \neq \\
>0.059\end{array}$ \\
\hline Urinary norepinephrine ( $\mu \mathrm{g} / 24 \mathrm{~h})$ & & & $16.9 \pm 6.2$ & & & $16.4 \pm 15.6$ & & & $17.4 \pm 8.4$ & $>0.05 \dagger, \neq$, , \\
\hline Urinary cortisol $(\mu \mathrm{g} / 24 \mathrm{~h})$ & & & $51.8 \pm 23.7$ & & & $46.7 \pm 24.1$ & & & $41.7 \pm 20.3$ & $>0.05 \dagger$,キ,Tा \\
\hline Plasma cortisol ( $\mu \mathrm{g} / \mathrm{dL})$ & & & $12.6 \pm 5.5$ & & & $14.1 \pm 18.3$ & & & $10.6 \pm 4.4$ & $>0.05 \dagger, \neq, q$ \\
\hline Thyroid stimulating hormone $(\mu \mathrm{IU} / \mathrm{mL})$ & & & $1.7 \pm 0.9$ & & & $2.0 \pm 1.5$ & & & $1.7 \pm 0.8$ & $>0.05 \dagger, \neq, \mathbb{T}$ \\
\hline $\mathrm{T} 3(\mathrm{pg} / \mathrm{mL})$ & & & $3.0 \pm 0.3$ & & & $3.1 \pm 0.4$ & & & $3.1 \pm 0.3$ & $>0.05 \dagger, \neq, \mathbb{T}$ \\
\hline $\mathrm{T} 4$ (ng/dL) & & & $1.1 \pm 0.1$ & & & $1.1 \pm 0.2$ & & & $1.1 \pm 0.1$ & $>0.05 \dagger, \neq, \mathbb{T}$ \\
\hline Iron $(\mu \mathrm{g} / \mathrm{dL})$ & & & $66.3 \pm 33.1$ & & & $66.0 \pm 27.2$ & & & $86.3 \pm 44.7$ & $>0.05 \uparrow, \neq, \mathbb{T}$ \\
\hline Ferritin $(\mathrm{ng} / \mathrm{mL})$ & & & $35.8 \pm 41.6$ & & & $21.9 \pm 20.1$ & & & $25.3 \pm 22.2$ & $>0.05 \dagger, \neq, \mathbb{Q}$ \\
\hline $\mathrm{B} 12(\mathrm{pg} / \mathrm{mL})$ & & & $300.9 \pm 146.9$ & & & $293.1 \pm 127.0$ & & & $318.0 \pm 125.8$ & $>0.05 \dagger, \neq, \mathbb{T}$ \\
\hline Folic acid $(\mathrm{ng} / \mathrm{mL})$ & & & $11.8 \pm 5.7$ & & & $10.8 \pm 4.2$ & & & $10.5 \pm 3.4$ & $\begin{array}{l}>0.05 \dagger, \neq,, T \\
>0.05 \dagger, \neq,, T\end{array}$ \\
\hline
\end{tabular}


Table 3. Univariate logistic regression analysis for MetS and its components in FMS patients

\begin{tabular}{lccc}
\hline & OR & $95 \% \mathrm{CI}$ & $p$ \\
\hline Metabolic syndrome & 3.76 & $1.04-13.4$ & 0.043 \\
Abdominal obesity & 3.19 & $1.33-7.65$ & 0.009 \\
High blood pressure & 2.49 & $0.99-6.22$ & 0.046 \\
Fasting hyperglycemia & 1.44 & $0.37-5.48$ & $>0.05$ \\
Hypertriglyceridemia & 3.47 & $1.13-10.66$ & 0.03 \\
Low HDL-cholesterol & 1.07 & $0.5-2.27$ & $>0.05$ \\
Waist/hip ratio risk & 2.6 & $1.04-6.49$ & 0.041 \\
HOMA risk & 3.2 & $1.12-9.14$ & 0.03 \\
\hline
\end{tabular}

MetS: Metabolic syndrome; FMS: Fibromyalgia syndrome; OR: Odds Ratios; CI: Confidence interval; HDL: High-density lipoprotein; HOMA: Homeostasis model assessment.

with a glycated hemoglobin risk level of $>5.5$ was $18(75 \%)$ in group $1,35(46.1 \%)$ in group 2 , and nine $(23.7 \%)$ in group $3(\mathrm{p}<0.001)$. The glycated hemoglobin risk levels were higher in both patient groups than the control group. The fasting plasma insulin and HOMA indexes were similar in FMS patients with and without MetS ( $p>0.005)$, while they were lower in the healthy controls $(p=0.03$ and $p=0.013$, respectively). The insulin resistance calculated with HOMA was present in 16 patients (66.7\%) in group 1, 25 patients (32.9\%) in group 2, and five individuals (13.2\%) in group $3(p=0.026$ and $\mathrm{p}>0.001$, respectively).

Table 3 presents the association between MetS components and FMS. Univariate logistic regression analysis was performed to assess the association between MetS or its individual components (independent variables) and FMS (dependent variables). There was a significant association between the occurrence of FMS and MetS (OR=3.76; 95\% CI: 1.04-13.4; $\mathrm{p}=0.043$ ). The number of MetS components was significantly higher in all the patients with FMS $(1.79 \pm 1.13)$ than the healthy controls $(1.13 \pm 1.06)(p=0.001)$. Additionally, the number of MetS components was found to be significantly correlated with the scores of symptom severity $(r=0.315$, $p=0.001)$ and widespread pain index $(r=0.428$, $\mathrm{p}<0.001)$ of the FMS patients. Abdominal obesity $(\mathrm{OR}=3.19 ; 95 \% \mathrm{CI}: 1.33-7.65 ; \mathrm{p}=0.009)$, high BP $(\mathrm{OR}=2.49 ; \quad 95 \%$ CI: $0.99-6.22 ; \quad \mathrm{p}=0.046)$ and hypertriglyceridemia $(\mathrm{OR}=3.47 ; 95 \% \mathrm{CI}$ : 1.13-10.66; $p=0.03$ ) components of MetS in FMS patients were significantly higher than the controls, but this significance was not observed in cases of low HDL and fasting hyperglycemia. Waist/hip ratio $(\mathrm{OR}=2.6$; 95\% CI: 1.04-6.49; $\mathrm{p}=0.041)$ and HOMA risk $(\mathrm{OR}=3.2 ; 95 \% \mathrm{CI}$ : $1.12-9.14 ; \mathrm{p}=0.03$ ) were higher in group 2 than group 3.

Table 4. Models obtained from stepwise linear regression analysis for Fibromyalgia Impact Questionnaire in FMS patients

\begin{tabular}{lccc}
\hline Model (Fibromyalgia Impact Questionnaire) & $R^{2}$ & Adjusted $R^{2}$ & Factors added \\
\hline FMS with MetS group & & & \\
1 & 0.564 & 0.533 & Beck depression inventory \\
2 & 0.763 & 0.726 & Diastolic blood pressure \\
3 & 0.875 & 0.844 & Systolic blood pressure \\
4 & 0.921 & 0.892 & Urinary norepinephrine \\
5 & 0.955 & 0.933 & Visual Analog Scale \\
FMS without MetS group & & & \\
1 & 0.450 & 0.439 & Fatigue severity scale \\
2 & 0.564 & 0.547 & Beck depression inventory \\
3 & 0.611 & 0.588 & Visual Analog Scale \\
4 & 0.647 & 0.619 & Fasting plasma insulin \\
\hline FMS: Fibromyalgia syndrome; MetS: Metabolic syndrome. & & &
\end{tabular}




\begin{tabular}{|c|c|c|c|c|c|c|}
\hline \multirow[b]{2}{*}{ Model (Fibromyalgia Impact Questionnaire) } & \multirow[b]{2}{*}{ B } & \multirow[b]{2}{*}{ SE } & \multirow[b]{2}{*}{$\beta$} & \multirow[b]{2}{*}{$p$} & \multicolumn{2}{|c|}{$95 \%$ CI for B } \\
\hline & & & & & Lower bound & Upper bound \\
\hline \multicolumn{7}{|l|}{ FMS with MetS group } \\
\hline Beck depression inventory & 0.937 & 0.105 & 0.704 & 0.00 & 0.703 & 1.171 \\
\hline Diastolic blood pressure & -0.744 & 0.133 & -0.758 & 0.00 & -1.040 & -0.448 \\
\hline Systolic blood pressure & 0.225 & 0.073 & 0.450 & 0.012 & 0.061 & 0.388 \\
\hline Urinary norepinephrine & -0.178 & 0.046 & -0.303 & 0.003 & -0.280 & -0.077 \\
\hline Visual Analog Scale & 4.597 & 1.659 & 0.221 & 0.020 & 0.900 & 8.294 \\
\hline \multicolumn{7}{|l|}{ FMS without MetS group } \\
\hline Fatigue severity scale & 0.515 & 0.100 & 0.508 & 0.00 & 0.315 & 0.716 \\
\hline Beck depression inventory & 0.317 & 0.109 & 0.295 & 0.005 & 0.098 & 0.536 \\
\hline Visual Analog Scale & 2.208 & 0.832 & 0.233 & 0.11 & 0.538 & 3.878 \\
\hline Fasting plasma insulin & 0.400 & 0.176 & 0.194 & 0.027 & 0.047 & 0.754 \\
\hline
\end{tabular}

Multivariate linear regression analyses were conducted to identify the affecting factors for current health status assessed with the FIQ. The models obtained from the regression analysis of the FIQ in FMS patients with and without MetS are shown in Tables 4 and 5 . In group 1 , regression analyses showed that increased $\mathrm{BDI}$ $\left(R^{2}=0.53\right)$, increased DBP $\left(R^{2}=0.09\right)$, increased $\operatorname{SBP}\left(R^{2}=0.12\right)$, decreased urinary $\mathrm{NE}\left(R^{2}=0.05\right)$, and increased VAS $\left(R^{2}=0.04\right)$ were associated with higher FIQ values. BDI was found to be a more prominent factor for FIQ score in group 1. In group 2, the regression analysis showed that increased FSS $\left(R^{2}=0.43\right)$, increased $\operatorname{BDI}\left(R^{2}=0.11\right)$, increased VAS $\left(R^{2}=0.04\right)$ scores, and increased fasting plasma insulin $\left(R^{2}=0.03\right)$ were associated with higher FIQ values. The FSS score was found to be a more prominent factor in FIQ values in patients without MetS (Tables 4 and 5).

\section{DISCUSSION}

In this study, we found that patients with FMS had a 3.76 times higher risk of MetS than demographically similar females without FMS. Several positive associations were found between FMS and MetS or its components, particularly in terms of abdominal obesity, hypertriglyceridemia, and high BP. Additionally, insulin resistance, which was calculated based on HOMA, and glycated hemoglobin risk levels were significantly higher in group 2 than group 3. The regression analyses showed that high BP and decreased urinary NE levels in group 1 and fasting plasma insulin levels in group 2 were associated with poor general health levels and increased levels of pain, depression, and fatigue. However, in the clinical practice, there are various limitations to determine insulin resistance such as the lack of a standardized universal insulin assay and the lack of data demonstrating that markers of insulin resistance have an effect on insulin treatment.

Loevinger et $a l .{ }^{8}$ found that patients with FMS were more prone to developing MetS with a 5.6 times higher risk than demographically similar females without chronic pain. Females with FMS presented with larger waist circumference, higher $\mathrm{BP}$, and higher levels of glycated hemoglobin and triglycerides. Both waist circumference and waist/hip ratio (but not BMI or weight) were higher in females with FMS. However, the authors did not report any relationship between MetS and pain severity or fatigue. ${ }^{8}$ In this study, we found that female patients with FMS had a 3.76 times higher risk of MetS than those without FMS. We found significant relationships between MetS and the pain and disease severity parameters of FMS; however, we did not identify any significant difference between the two patient groups regarding depression, fatigue or the FIQ values although these variables were different from the 
healthy controls. In recent years, clinical interest has shifted from depression to the influence of anxiety on pain perception and pain behavior, while in this study, we did not evaluate the anxiety level of our patients.

Both obesity and physical inactivity predispose to the development of insulin resistance, which is the hallmark of MetS. Visceral fat is also a central feature of this syndrome. The increased release of free fatty acids from visceral fat impairs insulin clearance by the liver and alters peripheral metabolism. The reduced production of adiponectin by the fat cells is another potential player in the development of insulin resistance. ${ }^{29,30}$ This condition is common in subjects with metabolic disorders, which is a driving force in the development of dyslipidemia and hypertension, although its prevalence varies among clinical conditions. ${ }^{31,32}$ Fava et al. ${ }^{10}$ showed that fibromyalgia patients with memory impairment had higher prevalence of insulin resistance than the control group. Insulin resistance was present in 79\% of patients with FMS and cognitive impairment. In the current study, we found that insulin resistance was significantly higher in FMS patients than in the control group despite the normal fasting glucose levels. Moreover, we found that FMS patients without MetS had a higher waist/ hip ratio and a higher insulin resistance rate than the healthy controls despite the similar mean BMI values. Therefore, we consider that insulin resistance may lead to predisposition to metabolic disturbances not only in FMS patients with MetS, but also in those without MetS.

It has been shown that there is a relationship between perceived stress, increased muscle tension, and elevated BP, as mediated by the sympathetic nervous system. ${ }^{33}$ In a study that assessed BP and metabolic factors in relation to chronic pain, it was found that subjects with widespread pain were more obese and had higher levels of fasting glucose, cholesterol, and office-measured SBP than the controls. ${ }^{34}$ Our regression analysis revealed that among the MetSrelated components, BP in FMS patients with MetS and fasting plasma insulin in FMS patients without MetS were related with the FIQ score. A systematic review showed that hypertensive patients had lower scores for the physical and mental components of Short Form 36. ${ }^{35}$ We observed that our FMS patients with and without MetS had uncontrolled hypertension, and a significant number of these patients had not taken any medication. We also observed that the higher FIQ scores were related with higher SBP and DBP values in FMS patients with MetS. Therefore, we consider that high BP is a serious problem for FMS patients besides other MetS components and is related to the poor general health of these patients.

Goodson et al. ${ }^{36}$ investigated the association between chronic pain and cardiovascular risk. Chronic pain was found to be associated with elevated cardiovascular disease risk scores calculated from the Framingham 10-year coronary heart disease risk. In another study, waist/hip ratio was reported as a significant predictor of acute myocardial infarction among males and females without an enlarged waist circumference. ${ }^{37}$ In our study, high waist/hip ratio, which is associated with cardiovascular risk, was found in all FMS patients with and without MetS. Therefore, it may be expected that the coexistence of MetS and FMS is an important risk factor for cardiovascular diseases and mortality. Similarly, Goodson et al. ${ }^{36}$ found that patients with the highest pain intensity had the highest prevalence of MetS. In a study by Andersson, ${ }^{38}$ chronic widespread pain was related with increased mortality. In this study, the FMS patients with MetS had more widespread and severe pain than the FMS patients without MetS. Additionally, we found that the FMS patients with MetS had higher disease severity. This suggests that MetS is a factor that increases the severity of FMS.

Fibromyalgia syndrome has often been described as a stress-related disorder. The body's two stress systems, hypothalamic-pituitaryadrenal axis and the sympathetic nervous system, are altered in FMS; however, the results on the specific changes are heterogeneous. ${ }^{39}$ For both systems, hyperactivity as well as hypoactivity in basal functioning and acute stress responses have been reported. ${ }^{39,40,41}$ Yunus et al. ${ }^{16}$ showed no significant differences between the FMS and control groups in terms of the catecholamine levels and found no correlation between the catecholamine levels and clinical features or psychological measures. In the current study, we did not identify any difference between the three groups regarding the urinary cortisol, NE, 
and plasma cortisol levels. Additionally, there was no correlation between urinary and plasma cortisol levels and clinical features of FMS. Adler et al. ${ }^{42}$ showed that females with FMS had normal 24-hour urinary free cortisol levels and normal diurnal patterns of adrenocorticotropic hormone and cortisol. The epinephrine response to hypoglycemia correlated negatively with overall health status as measured by the FIQ in fibromyalgia patients. In a study by Riva et al., ${ }^{43}$ urinary catecholamines and heart rate were assessed for a 24-hour period in a controlled hospital setting. The authors found that single time point $\mathrm{NE}$ levels were not significantly different between the female FMS and control groups. On the other hand, we found a negative relationship between FIQ and urinary NE levels in the FMS patients. Our FMS patients with MetS had taken more antidepressant medications than our FMS patients without MetS. In the literature, it was shown that antidepressants reduced the whole body NE turnover while enhancing the 6-hydroxymelatonin output. ${ }^{44}$ Therefore, we were not able to interpret this finding. Additionally, weight gain is a very common problem during antidepressant treatment, and this leads to patient noncompliance. ${ }^{45}$ However, in this study, we did not consider weight gain or effect of medication on BMI.

Loevinger et al. ${ }^{46}$ identified four distinct subgroups in FMS patients: Subgroup I exhibited childhood maltreatment and hypocortisolism. Subgroup II exhibited more physiological dysregulation, high levels of pain, fatigue, disability, and warning signs of MetS. Subgroup III was characterized by normal biomarkers and intermediate pain severity. Finally, subgroup IV exhibited less disability, pain, and psychological well being. These subgroups had nearly identical tender point counts. In our patient group with FMS and MetS, we mostly observed subgroup II features except hypocortisolism. This subgroup analysis may help select patient-specific treatment approaches.

This study has some limitations. We did not evaluate the anxiety level of our patients. Moreover, we did not consider weight gain or effect of medication on BMI. Other limitations are the lack of assessment of sleep disturbance and physical activity levels of the patients.
In conclusion, we found that the patients with FMS had a nearly four times higher risk for MetS and the coexisting MetS may increase the severity of FMS. In clinical practice, when evaluating a patient with fibromyalgia, metabolic characteristics should also be evaluated.

\section{Declaration of conflicting interests}

The authors declared no conflicts of interest with respect to the authorship and/or publication of this article.

\section{Funding}

The authors received no financial support for the research and/or authorship of this article.

\section{REFERENCES}

1. Ursini F, Naty S, Grembiale RD. Fibromyalgia and obesity: the hidden link. Rheumatol Int 2011;31:1403-8.

2. Arendt-Nielsen L, Graven-Nielsen T. Central sensitization in fibromyalgia and other musculoskeletal disorders. Curr Pain Headache Rep 2003;7:355-61.

3. Okifuji A, Donaldson GW, Barck L, Fine PG. Relationship between fibromyalgia and obesity in pain, function, mood, and sleep. J Pain 2010;11:1329-37.

4. Wallace DJ. Is there a role for cytokine based therapies in fibromyalgia. Curr Pharm Des 2006;12:17-22.

5. Park YW, Zhu S, Palaniappan L, Heshka S, Carnethon MR, Heymsfield SB. The metabolic syndrome: prevalence and associated risk factor findings in the US population from the Third National Health and Nutrition Examination Survey, 1988-1994. Arch Intern Med 2003;163:427-36.

6. Wilson JF. Is sleep the new vital sign? Ann Intern Med 2005;142:877-80.

7. Henriksson CM. Longterm effects of fibromyalgia on everyday life. A study of 56 patients. Scand J Rheumatol 1994;23:36-41.

8. Loevinger BL, Muller D, Alonso C, Coe CL. Metabolic syndrome in women with chronic pain. Metabolism 2007; 56:87-93.

9. Okifuji A, Bradshaw DH, Olson C. Evaluating obesity in fibromyalgia: neuroendocrine biomarkers, symptoms, and functions. Clin Rheumatol 2009;28:475-8.

10. Fava A, Plastino M, Cristiano D, Spanò A, Cristofaro $\mathrm{S}$, Opipari $\mathrm{C}$, et al. Insulin resistance possible risk factor for cognitive impairment in fibromialgic patients. Metab Brain Dis 2013;28:619-27.

11. Yanmaz MN, Mert M, Korkmaz M. The prevalence of fibromyalgia syndrome in a group of patients with diabetes mellitus. Rheumatol Int 2012;32:871-4.

12. Grundy SM, Brewer HB Jr, Cleeman JI, Smith SC Jr, Lenfant C; American Heart Association; National Heart, Lung, and Blood Institute. Definition 
of metabolic syndrome: Report of the National Heart, Lung, and Blood Institute/American Heart Association conference on scientific issues related to definition. Circulation 2004;109:433-8.

13. Brunner EJ, Hemingway $\mathrm{H}$, Walker BR, Page M, Clarke P, Juneja M, et al. Adrenocortical, autonomic, and inflammatory causes of the metabolic syndrome: nested case-control study. Circulation. 2002;106:2659-65.

14. Martínez-Lavín M, Hermosillo AG. Autonomic nervous system dysfunction may explain the multisystem features of fibromyalgia. Semin Arthritis Rheum 2000;29:197-9.

15. Corry DB, Tuck ML. Obesity, hypertension, and sympathetic nervous system activity. Curr Hypertens Rep 1999;1:119-26.

16. Yunus MB, Dailey JW, Aldag JC, Masi AT, Jobe PC. Plasma and urinary catecholamines in primary fibromyalgia: a controlled study. J Rheumatol 1992;19:95-7.

17. Demitrack MA, Crofford LJ. Evidence for and pathophysiologic implications of hypothalamicpituitary-adrenal axis dysregulation in fibromyalgia and chronic fatigue syndrome. Ann N Y Acad Sci 1998;840:684-97.

18. FriesE, Hesse J, HellhammerJ, Hellhammer DH. Anew view on hypocortisolism. Psychoneuroendocrinology 2005;30:1010-6.

19. Wolfe F, Clauw DJ, Fitzcharles MA, Goldenberg DL, Katz RS, Mease P, et al. The American College of Rheumatology preliminary diagnostic criteria for fibromyalgia and measurement of symptom severity. Arthritis Care Res (Hoboken) 2010;62:600-10.

20. Obesity and Overweight - World Health Organization. Factsheet No. 311. Geneva: September 2006.

21. WHO consultation on Obesity. Obesity: Preventing and Managing the Global Epidemic. Geneva, Switzerland: Division of Noncommunicable Diseases Programme of Nutrition. Family and Reproductive Health. World Health Organization; 1998.

22. Matthews DR, Hosker JP, Rudenski AS, Naylor BA, Treacher DF, Turner RC. Homeostasis model assessment: insulin resistance and beta-cell function from fasting plasma glucose and insulin concentrations in man. Diabetologia 1985;28:412-9.

23. Blake GJ, Pradhan AD, Manson JE, Williams GR, Buring J, Ridker PM, et al. Hemoglobin A1c level and future cardiovascular events among women. Arch Intern Med 2004;164:757-61.

24. Beck AT, Steer RA. Internal consistencies of the original and revised Beck Depression Inventory. J Clin Psychol 1984;40:1365-7.

25. Beck AT, Steer RA, Carbin GM. Psychometric properties of the Beck Depression Inventory: Twenty-five years of evaluation. Clinical Psychology Review 1988;8:77-100.

26. Fisher AA. Clinical use of tissue compliancemeter for documentation of soft tissue pathology. Clin J Pain 1987;3:23-30.
27. Gencay-Can A, Can SS. Validation of the Turkish version of the fatigue severity scale in patients with fibromyalgia. Rheumatol Int 2012;32:27-31.

28. Sarmer S, Ergin S, Yavuzer G. The validity and reliability of the Turkish version of the Fibromyalgia Impact Questionnaire. Rheumatol Int 2000;20:9-12.

29. Ray L, Lipton RB, Zimmerman ME, Katz MJ, Derby CA. Mechanisms of association between obesity and chronic pain in the elderly. Pain 2011;152:53-9.

30. Bray GA, Bellanger T. Epidemiology, trends, and morbidities of obesity and the metabolic syndrome. Endocrine 2006;29:109-17.

31. Bonora E, Kiechl S, Willeit J, Oberhollenzer F, Egger $G$, Targher G, et al. Prevalence of insulin resistance in metabolic disorders: the Bruneck Study. Diabetes 1998;47:1643-9.

32. Laws A, Reaven GM. Insulin resistance and risk factors for coronary heart disease. Baillieres Clin Endocrinol Metab 1993;7:1063-78.

33. Isaksson H, Danielsson M, Rosenhamer G, KonarskiSvensson JC, Ostergren J. Characteristics of patients resistant to antihypertensive drug therapy. $\mathrm{J}$ Intern Med 1991;229:421-6.

34. Nilsson PM, Kandell-Collén A, Andersson HI. Blood pressure and metabolic factors in relation to chronic pain. Blood Press 1997;6:294-8.

35. Trevisol DJ, Moreira LB, Kerkhoff A, Fuchs SC, Fuchs FD. Health-related quality of life and hypertension: a systematic review and meta-analysis of observational studies. J Hypertens 2011;29:179-88.

36. Goodson NJ, Smith BH, Hocking LJ, McGilchrist MM, Dominiczak AF, Morris A, et al. Cardiovascular risk factors associated with the metabolic syndrome are more prevalent in people reporting chronic pain: results from a cross-sectional general population study. Pain 2013;154:1595-602.

37. Egeland GM, Igland J, Vollset SE, Sulo G, Eide GE, Tell GS. High population attributable fractions of myocardial infarction associated with waist-hip ratio. Obesity (Silver Spring) 2016;24:1162-9.

38. Andersson HI. Increased mortality among individuals with chronic widespread pain relates to lifestyle factors: a prospective population-based study. Disabil Rehabil 2009;31:1980-7.

39. Becker S, Schweinhardt P. Dysfunctional neurotransmitter systems in fibromyalgia, their role in central stress circuitry and pharmacological actions on these systems. Pain Res Treat 2012;2012:741746.

40. Martinez-Lavin M. Biology and therapy of fibromyalgia. Stress, the stress response system, and fibromyalgia. Arthritis Res Ther 2007;9:216.

41. Stein PK, Domitrovich PP, Ambrose K, Lyden A, Fine M, Gracely $\mathrm{RH}$, et al. Sex effects on heart rate variability in fibromyalgia and Gulf War illness. Arthritis Rheum 2004;51:700-8. 
42. Adler GK, Kinsley BT, Hurwitz S, Mossey CJ, Goldenberg DL. Reduced hypothalamic-pituitary and sympathoadrenal responses to hypoglycemia in women with fibromyalgia syndrome. Am J Med 1999;106:534-43.

43. Riva R, Mork PJ, Westgaard RH, Okkenhaug Johansen $\mathrm{T}$, Lundberg U. Catecholamines and heart rate in female fibromyalgia patients. J Psychosom Res 2012;72:51-7.

44. Golden RN, Markey SP, Risby ED, Rudorfer MV, Cowdry RW, Potter WZ. Antidepressants reduce whole-body norepinephrine turnover while enhancing 6-hydroxymelatonin output. Arch Gen Psychiatry 1988;45:150-4.

45. Fava M. Weight gain and antidepressants. J Clin Psychiatry 2000;61 Suppl 11:37-41.

46. Loevinger BL, Shirtcliff EA, Muller D, Alonso C, Coe CL. Delineating psychological and biomedical profiles in a heterogeneous fibromyalgia population using cluster analysis. Clin Rheumatol 2012;31:677-85. 